Research Article

\title{
Zinc Oxide Nanoparticles and Nanorods as Antimicrobial Agents: Particle Size Influence
}

\author{
Araa Mebdir Holi ${ }^{1}$, Sadiyha Yasir Offi Al-Jubory ${ }^{2}$ \\ ${ }^{1}$ Department of Physics, College of Education, University of Al-Qadisiyah, Al-Diwaniyah, Al-Qadisiyah, 58002, Iraq. \\ ${ }^{2}$ Department of Agricultural Biotechnology, College of Biotechnology, University of Al-Qadisiyah, Al-Diwaniyah, Al-Qadisiyah, \\ 58002, Iraq. \\ $\because$ Corresponding author. E-mail: araa.holi@qu.edu.iq; Tel.: +9647823145910
}

Received: Nov. II, 2019; Accepted: Dec. 10, 2019; Published: Dec. II, 2019.

Citation: Araa Mebdir Holi, Sadiyha Yasir Offi Al-Jubory, Zinc Oxide Nanoparticles and Nanorods as Antimicrobial Agents: Particle Size Influence. Nano Biomed. Eng., 2019, I I (4): 375-380.

DOI: $10.5101 /$ nbe.v11i4.p375-380.

\begin{abstract}
The aim of this study is to find out about the antibacterial activity of a variety of $\mathrm{ZnO}$ nanostructures, along with their derivative nanoparticles ( $\mathrm{ZnO} \mathrm{NPs}$ ) and nanorods ( $\mathrm{ZnO} \mathrm{NRs}$ ) against numerous clinic strains of Gram-negative Escherichia coli (E. coli), Salmonella typhi (S. typhi), Pseudomonas aeruginosa (P. aeruginosa) as well as Gram-positive Streptococcus pneumonia (Strept. pneumonia) bacteria. ZnO NPs and ZnO NRs were efficiently synthesized by using sol-gel and hydrothermal strategies, respectively. Various properties, consisting of the morphology, structure and optical, had been described by using field emission scanning electron microscopy (FESEM), X-ray diffraction (XRD) as well as ultraviolet-visible (UV-Vis) spectroscopy analysis. This check was performed in Mueller-Hinton agar. The impact of different particle sizes and morphologies of $\mathrm{ZnO}$ nanomaterials on the growth of bacteria was measured. In the antibacterial assay, each type of $\mathrm{ZnO}$ nanostructure showed effective inhibition. The findings showed that $\mathrm{ZnO}$ NRs exhibited more efficient antibacterial activity than that of ZnO NPs agents. This was once the case for both Gram-positive and Gramnegative bacteria. Hence, the study indicated that the antibacterial of $\mathrm{ZnO}$ NRs against Strept. Pneumonia was similar to those for S. typhi. However, depending on the particle size effect of $\mathrm{ZnO}$ nanostructure, it was found that $\mathrm{ZnO}$ NPs showed much less antibacterial activity towards $S$. typhi than $\mathrm{ZnO}$ NRs did.
\end{abstract}

Keywords: $\mathrm{ZnO}$ nanoparticles; $\mathrm{ZnO}$ nanorods; Particle size; Antibacterial activity

\section{Introduction}

As well known in scientific fields, zinc oxide $(\mathrm{ZnO})$ is a metal oxide with a wide variety of applications in various fields like optics, piezoelectricity, sensing of gas and magnetics. One of the key features of zinc oxide nanostructures is its high catalytic effectiveness, powerful adsorption ability as well as its widespread utilization in sunscreen manufacture [1]. The nanoparticles of zinc oxide, i.e. ZnO NPs, have been globally synthesized due to these convenient properties, justifying their utilization in many diverse fields, including nano diagnostics [2,3], nanomedicine $[4,5]$, antimicrobials [6], and immune toxicity [7]. $\mathrm{ZnO}$ NPs have gotten noteworthy attention because of their additional usual ultraviolet (UV) filtering characteristic, antibacterial and high catalytic activities, photochemical antifungal. Moreover, it is a provocative material for applications in gadgets, photonics, acoustics, photovoltaic and photodetectors [8]. Most significant properties of $\mathrm{ZnO}$ have been stated in the work by Abd Elhady [9], where is was inferred 
that $\mathrm{ZnO}$ nanorods ( $\mathrm{ZnO} \mathrm{NRs}$ ) had UV protection phenomena and antibacterial activities. A various, lowcost, easy, and considerable of techniques have been utilized to prepare $\mathrm{ZnO}$ in distinct morphologies and sizes for diverse applications, such as oxidation of metallic zinc powder [10], sol-gel method [11], pulsed laser deposition [12], hydrothermal synthesis [13], chemical vapor deposition [14], electrodeposition [15], and a sputtering method [16].

The antimicrobial activity of zinc oxide nanoparticles has been studied by various researchers [17-19]. But we used two ZnO nanostructures (nanoparticles and nanorods) in the present study to investigate the impact of particle size and morphology on antimicrobial performance. Therefore, $\mathrm{ZnO}$ has been put under the spotlight lately due to its easimess to prepare and its antimicrobial and antifungal processes even with lower concentrations. These features make it feasible for various thin coating applications as well [20]. As claimed via the U.S. Food and Drug Administration (FDA) (21CFR182.8991), $\mathrm{ZnO}$ is dubbed "generally documented as safe" (GRAS). Further, they have been shown to possess a diverse set of antibacterial processes against Gram-positive and -negative bacteria, comprising predominant foodborne pathogens such as Salmonella, Escherichia coli O157: H7, and Staphylococcus aureus [21, 22]. Utilization of antibiotics poses many facet effects, some of which consist of a rise in bacterial resistance [23, 24]. Due to the aforementioned details, the current study sought to check the inhibitory impact of ZnO NPs and ZnO NRs towards bacteria.

\section{Experimental}

\section{Preparation of $\mathrm{ZnO}$ nanoparticles and $\mathrm{ZnO}$ nanorod arrays}

Sol-gel approach was utilized to set up zinc oxide nanoparticles through mixing $0.1 \mathrm{M}$ of ethanolic solution of zinc acetate alongside with $0.1 \mathrm{M}$ of diethanolamine. In order to nurture a homogeneous and secure colloid solution, the mixture was stirred at $60{ }^{\circ} \mathrm{C}$ for $30 \mathrm{~min}$. Afterward, it was left to ensure getting aging overnight. Furthermore, hydrothermal manner was used to prepare zinc oxide nanorods. It was the subsequent method to put together zinc oxide nanoparticles by using mixing an aqueous solution of $0.04 \mathrm{M}$ zinc nitrate $\mathrm{Zn}\left(\mathrm{NO}_{3}\right)_{2}$ and $0.04 \mathrm{M}$ hexamethylenetetramine (HMTA). The hydrothermal method was executed at the temperature of $90{ }^{\circ} \mathrm{C}$ with the employment of a digital oven and constant increase time of $4 \mathrm{~h}$.

\section{Antibacterial}

Antibacterial activity of zinc oxide nanoparticles and nanorods was examined against hospital strain of Gram-negative E. coli, S. typhi, P. aeruginosa as well as Gram-positive Strept. pneumonia bacteria. These bacteria were received from the Diwaniyah Teaching Hospital and ensured to be diagnostic in the University of Al-Qadisiyah/College of Biotechnology/Iraq. Strains were maintained on nutrient agar for further study.

\section{Agar well diffusion assay}

The Agar well diffusion approach was utilized to filter the antibacterial endeavor of the synthesized $\mathrm{ZnO}$ NPs and ZnO NRs. Wells that had been constructed using a sterile cork borer $(6 \mathrm{~mm})$ bored into the Mueller-Hinton Agar (Himedia). Bacterial suspensions were organized with a turbidity of 0.5 McFarland standards (cell density $=1 \times 10^{8} \mathrm{CFU} / \mathrm{Ml}$ ) and $100 \mu \mathrm{L}$ from suspension were swabbed onto the petri dish. The wells were filled with $100 \mu \mathrm{L}$ ZnO NPs and ZnO NRs from a range of concentrations of 25, 50, 75, 100\% by means of micropipette and plates. Next, they were incubated at $37{ }^{\circ} \mathrm{C}$ for $24 \mathrm{~h}$. The antibacterial activity was estimated by calculating the inhibition zone of the check microorganisms. All the exams were performed in triplicates underneath sterile condition. Gentamicin was once utilized as an advantageous control.

\section{Characterizations}

The crystallite structures of zinc oxide nanoparticles and nanorods were investigated using X-ray diffractometer (XRD) (Panalytical X'Pert Pro) by using $\mathrm{CuK} \alpha$ radiation $(\lambda=1.54 \AA)$ at $40 \mathrm{kV}$ and $40 \mathrm{~mA}$. Moreover, the samples' morphology was examined through field emission scanning electron microscopy (FESEM) analysis (JEOL JSM-7600F). Next, the absorbance spectra of the equipped samples were tested by Perkin Elmer Lambda 20 UV-Visible spectrophotometer.

\section{Results and Discussion}

\section{XRD analysis}

Fig. 1 illustrates the XRD results for $\mathrm{ZnO}$ nanoparticles and nanorods which were heat-treated using indium tin oxide (ITO) glass substrates. Each sample's peaks may be indexed as pure zinc oxide wurtzite structure [JCPDS: 00-003-0888]. In addition 


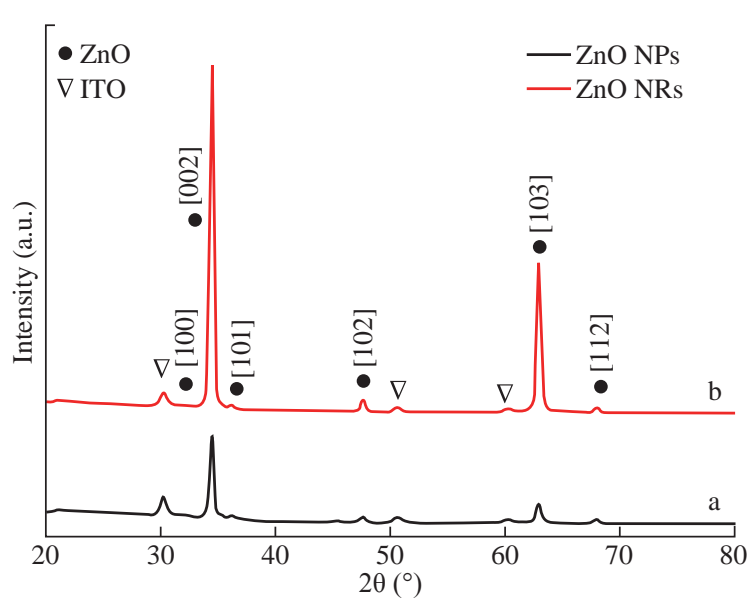

Fig. 1 XRD diffractogram of (a) ZnO NPs and (b) ZnO NRs.

to these peaks, only ITO peaks [JCPDS: 01-089-4598] that belongs to substrates were observed. Starting of the X-ray line broadening of zinc oxide nanoparticles contrasted with $\mathrm{ZnO}$ nanorods, the crystallization sizes were obtained using $\mathrm{D}=0.94 \lambda / \beta \cos \theta$ : where $\lambda$ is the $\mathrm{X}$-ray wavelength, $\theta$ is the Bragg angle, and $\beta$ is the full width at half maximum (FWHM)) of the diffraction peak which was $19.1 \mathrm{~nm}, 22.2 \mathrm{~nm}$, respectively. The rise of (002) peak for zinc-oxide samples exhibiting anisotropic behavior could be observed in Fig. 1(a) and (b) which confirmed that the suitable orientation of both samples was in the c-axis direction.

\section{FESEM images}

Multiple morphologies of zinc oxide nanoparticles and nanorods were made quite apparent, as shown in Fig. 2 displaying FESEM images. Moreover, the mean samples' particle size was located to be $20 \pm 5$ $\mathrm{nm}$, while for $\mathrm{ZnO} \mathrm{NRs}$, the mean length was observed to be $700 \pm 50 \mathrm{~nm}$ and the diameter to be $60 \pm 5 \mathrm{~nm}$. As expected, surface area of the $\mathrm{ZnO}$ NRs was found to be much greater than that of ZnO NPs, which is apparent in Fig. 2(b). Additionally, the particle size values of both $\mathrm{ZnO}$ morphologies could be clearly observed.

\section{Ultraviolet-visible spectrum}

The plot of absorbance spectra for both zinc oxide nanoparticles and nanorods are displayed in Fig. 3. It could be noted that the absorbance edge shifted a little towards longer wavelengths. Thus, it could be inferred that the absorbance of materials was influenced by particle size. The absorbance spectra showed absorption peaks of $\mathrm{ZnO}$ nanoparticles and nanorods at wavelengths of $387 \mathrm{~nm}$ and $393 \mathrm{~nm}$, respectively, which could be attributed to the fundamental bandgap of $\mathrm{ZnO}$ (as shown in the inset Fig. 3) owing to the

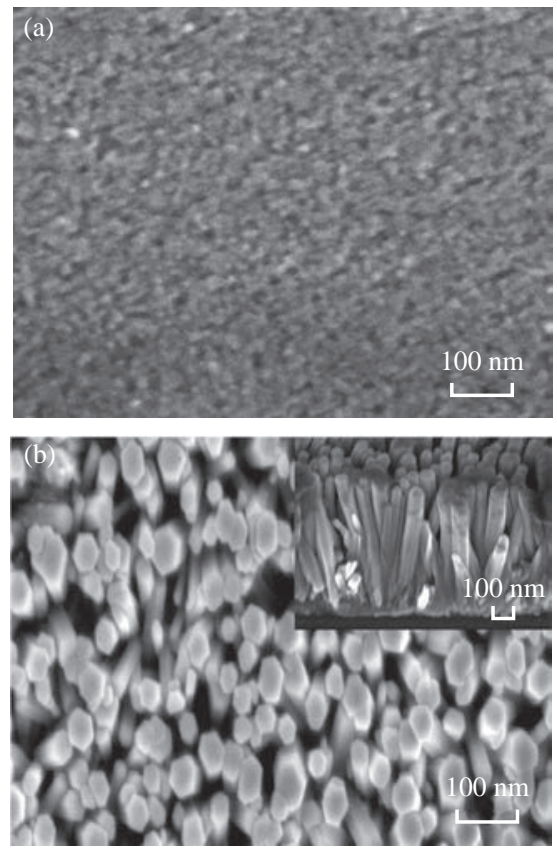

Fig. 2 FESEM images of (a) ZnO NPs (top view) and (b) $\mathrm{ZnO} \mathrm{NRs}$ (top view), with inset image of cross sectional.

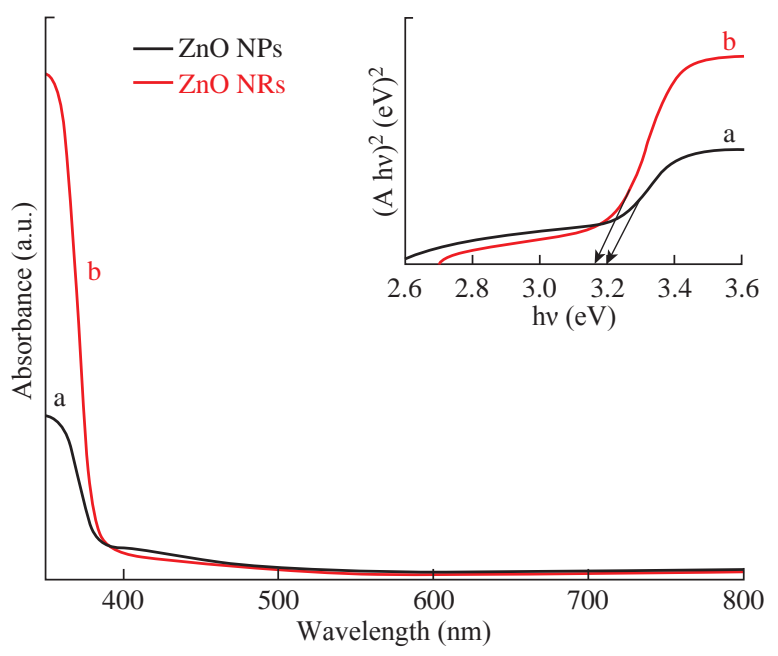

Fig. 3 UV-Vis spectra and band gap energy curves (shown in an inset of the figure) of (a) ZnO NPs and (b) ZnO NRs.

transition of electrons from the valence band (VB) to the conduction band (C-B).

\section{Antimicrobial activity}

The antibacterial impact of $\mathrm{ZnO}$ (NPs and NRs) was gauged via obtaining the zone of inhibition (displayed in Table 1) versus the studied pathogenic strains. Findings showed that zinc oxide nanoparticles and nanorods exhibited effective antibacterial activity for all strains tested. In general, the findings illustrated that the inhibitory effect of zinc oxide nanoparticles and nanorods rose proportionally with higher concentrations. The bacteria tested exhibited 
Table 1 Antimicrobial activity of $\mathrm{ZnO}$ NRs and $\mathrm{ZnO}$ NPs against different bacteria. Diameter of inhibition zone is mm. G: Gentamycin

\begin{tabular}{|c|c|c|c|c|}
\hline \multirow{2}{*}{ Sample } & \multicolumn{4}{|c|}{ Inhibition zone diameter (mm) } \\
\hline & E. coli & S. typhi & P. aeruginosa & Strept. pneumonia. \\
\hline $25 \% \mathrm{ZnO} \mathrm{NPs}$ & 10 & 0.0 & 11 & 29 \\
\hline $50 \% \mathrm{ZnO} \mathrm{NPs}$ & 12 & 0.0 & 16 & 29 \\
\hline $75 \% \mathrm{ZnO} N \mathrm{Ns}$ & 14 & 14 & 18 & 30 \\
\hline $100 \% \mathrm{ZnO}$ NPs & 23 & 15 & 17 & 30 \\
\hline $25 \% \mathrm{ZnO} \mathrm{NRs}$ & 13 & 12 & 11 & 12 \\
\hline $50 \% \mathrm{ZnO}$ NRs & 15 & 30 & 16 & 29 \\
\hline $75 \% \mathrm{ZnO}$ NRs & 18 & 30 & 16.5 & 30 \\
\hline $100 \% \mathrm{ZnO}$ NRs & 30 & 40 & 20 & 40 \\
\hline G & 20 & 17 & 17 & 22 \\
\hline
\end{tabular}

higher sensitivity towards the synthesized zinc oxide nanoparticles and nanorods (Fig. 4 and 5). All the tested bacteria were found to be relatively more sensitive to zinc oxide nanoparticles and nanorods when compared to antibiotics. Similar findings were shown by Fair and Tor [25], where it was shown that the synthesized zinc oxide nanoparticles exhibited improved antimicrobial activities than synthetic drugs did for Gram-positive and -negative bacteria. The findings have confirmed that the small size of nanoparticles is supporting the ease of entering microbial cell membrane and thereby allowing inhibition mechanisms to activate within the

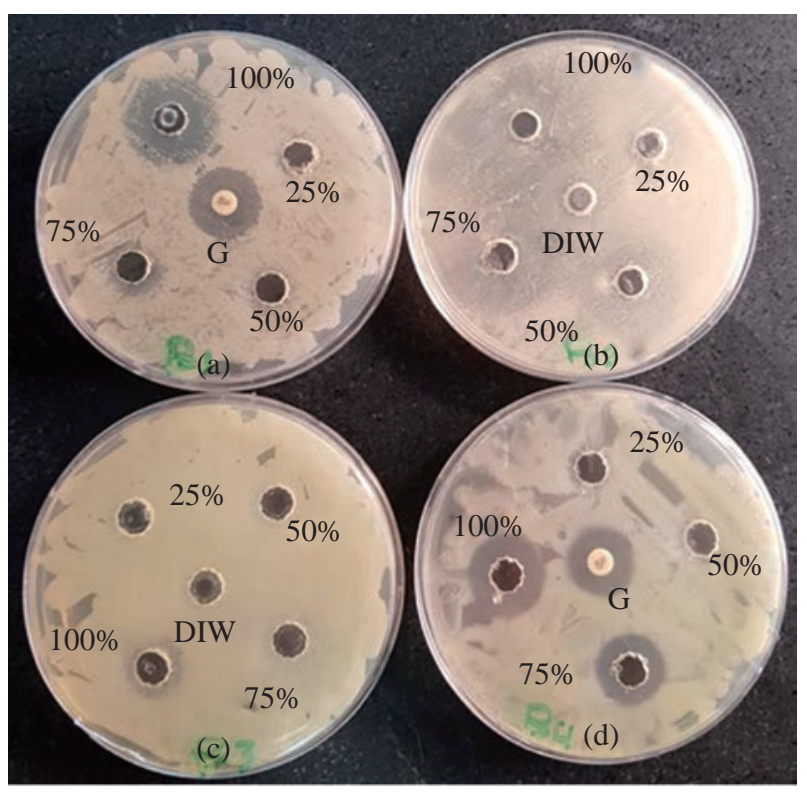

Fig. 4 Antibacterial activity of $\mathrm{ZnO}$ NPs against (a) E. coli, (b) Strept. Pneumonia, (c) S. typhi, and (d) P. aeruginosa, at different concentrations. G: Antibiotic (Gentamycin); DIW: Deionize water.

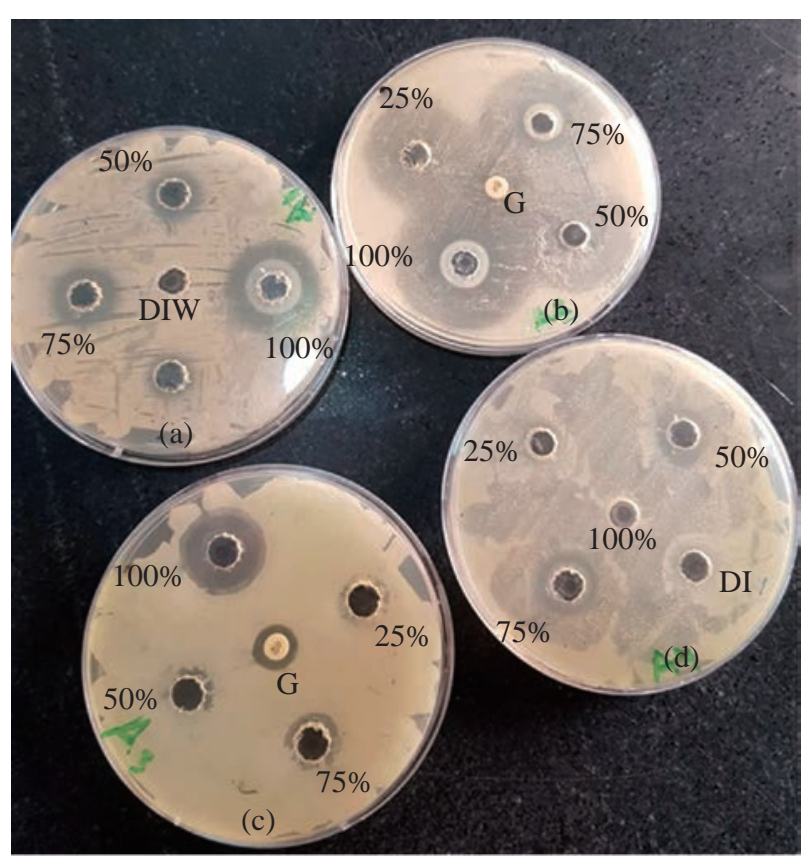

Fig. 5 Antibacterial activity of $\mathrm{ZnO}$ NRs against (a) E. coli, (b) S. typhi, (c) P. aeruginosa, and (d) Strept. Pneumonia at different concentrations. G: Antibiotic (Gentamycin); DIW: Deionize water.

cell [26]. It may also be explained by the involvement of reactive oxygen species (ROS) production $[27$, 28], and accumulation of nanoparticles within the cytoplasm or outer membranes [29, 30], disruption of the cell membrane and oxidative stress [31]. Findings illustrate that Gram-positive bacteria (Strept. pneumoniae) exhibited higher sensitivity to zinc oxide nanoparticles and nanorods than Gram-negative bacteria. Another explanation may additionally be due to the differing nature of surface membranes for the range of bacteria current [32]. 
The previous work results exhibited that the antibacterial activity of ZnO NPs increased when sizes of the particle were small with high concentrations based on the time effect. Additionally, $\mathrm{ZnO}$ nanorods were observed to have been further effective than $\mathrm{ZnO}$ nanoparticles. One clarification for this finding might be because of antibacterial impact contingent upon some parameters, for example, particle size, morphology, surface functionality, and fabrication, that has resulted from the large of the surface area of $\mathrm{ZnO}$ NRs compared with $\mathrm{ZnO}$ NPs. Because of the increasing of touching the surface area that is a significant condition for the effects of nanoparticles shapes [33, 34], consequently, the functional activity of nanoparticles has been strongly influenced by their size. Based on this, the antimicrobial activity of $\mathrm{ZnO}$ on bacteria has been enhanced with a diminution of particle size $[35,36]$. This used to be interpreted due to the fact of an excess in the surface area to volume, which resulted in the increment reactivity of $\mathrm{ZnO}$ surface in nanometer-size. Previous studies [37-39] reported that aqueous suspensions of small nanoparticles of $\mathrm{ZnO}$ produced improved levels of reactive oxygen species, particularly hydroxyl radicals with the accumulation of nanoparticles.

It may additionally be concluded from the consequence that $\mathrm{ZnO}$ NPs and ZnO NRs are well contenders for performing as antibacterial agents for each Gram-positive and Gram-negative bacterium. Based on that, antimicrobial casings are of significant attention for safeguard of the surfaces, because of the existence of microorganisms on superficies in the environment can diffuse diseases [40].

\section{Conclusions}

The multitude of antibacterial activity for zinc oxide nanomaterials possessing various morphology was highlighted in the current study. The antibacterial activity of $\mathrm{ZnO}$ nanorods was found to be greater than their nanoparticle counterparts. Variations in antibacterial activity against $S$. typhi was found to be commensurate to those against E. coli. Nevertheless, when considering the particle size impact on impedance microbiology, Letch-antibacterial activity was found to be much less than its worth and closer to S. typhi. Hence, the occurrence of antibacterial activity may need to be defined via the generation of $\mathrm{H}_{2} \mathrm{O}_{2}$ from the surface of $\mathrm{ZnO}$.

\section{Acknowledgements}

We thank the University of Al-Qadisiyah/ College of Education and College of Biotechnology / Ministry of Higher Education and Scientific Research of Iraq for finical supportfor this study. Special thanks are extended to Diwaniyah Teaching Hospital.

\section{References}

[1] G. Sangeetha, R. Sivaraj, and V. Rajendran, Green synthesized $\mathrm{ZnO}$ nanoparticles against bacterial and fungal pathogens. Progress in Natural Science: Materials International, 2012, 22: 693-700.

[2] J. Pragati, P. Khatri, and J.S. Rana, Green synthesis of zinc oxide nanoparticles using flower extract of Nyctanthes arbor-tristis and their antifungal activity. Journal of King Saud University-Science, 2018, 30: 168-175.

[3] R. Kimia, M. Etemadzade, R. Farhoudi, et al., Fe ${ }^{3+}-$ EDTA-zinc oxide nano-diagnostics: Synthesis and in vitro cellular evaluation. An International Peer Reviewed Open Access Journal for Rapid Publication, 2017: 445.

[4] J. Jinhuan, J. Pi, and J. Cai, The advancing of zinc oxide nanoparticles for biomedical applications. Bioinorganic chemistry and applications, 2018, 2018.

[5] K.I. Bogutska, Y.P. Sklyarov, and Y.I. Prylutskyy, Zinc and zinc nanoparticles: biological role and application in biomedicine. Ukrainica Bioorganica Acta, 2013, 1: 9-16.

[6] K. Rajesh, A. Umar, G. Kumar, et al., Antimicrobial properties of $\mathrm{ZnO}$ nanomaterials. A review Ceramics International, 2017, 43: 3940-3961.

[7] K. Cheol-Su, H.D. Nguyen, R.M. Ignacio, et al., Immunotoxicity of zinc oxide nanoparticles with different size and electrostatic charge. International Journal of Nanomedicine, 2014, 9: 195.

[8] P. Uikey, K. Vishwakarma, Review of zinc oxide ( $\mathrm{ZnO})$ nanoparticles applications and properties. International Journal of Emerging Technology in Computer Science \& Electronics, 2016, 21: 239.

[9] M.M. Abd Elhady, Preparation and characterization of chitosan/zinc oxide nanoparticles for imparting antimicrobial and UV protection to cotton fabric. International Journal of Carbohydrate Chemistry, 2012, 2012.

[10] S. Noothongkaew, S. Pukird, W. Sukkabot, et al., Zinc oxide nanostructures synthesized by thermal oxidation of zinc powder on Si substrate. Applied Mechanics and Materials, 2013, 328: 710-714.

[11] A.M. Holi, Z. Zainal, Z.A. Talib, et al., Effect of hydrothermal growth time on $\mathrm{ZnO}$ nanorod arrays photoelectrode performance. Optik, 2016, 127: 1111111118.

[12] Y.Y. Villanueva, D.R. Liu, and P.T. Cheng, Pulsed laser deposition of zinc oxide. Thin Solid Films, 2006, 501: 366-369.

[13] J. Zhang, T. Liu, Y. Zhang, et al., Hydrothermal synthesis and growth mechanisms of different $\mathrm{ZnO}$ nanostructures and their gas-sensing properties. Journal of Materials Science: Materials in Electronics, 2015, 26: 1347-1353.

[14] Z. Chen, K. Shum, T. Salagaj, et al., ZnO thin films synthesized by chemical vapor deposition. Proceedings of the 2010 IEEE Long Island Systems, Applications and Technology Conference, 2010: 1-6.

[15] A. Goux, T. Pauporté, J. Chivot, et al., Temperature effects on $\mathrm{ZnO}$ electrodeposition. Electrochimica Acta, 2005, 50: 2239-2248. 
[16] T. Shimomura, D. Kim, and M. Nakayama, Optical properties of high-quality $\mathrm{ZnO}$ thin films grown by a sputtering method. Journal of Luminescence, 2005, 112: 191-195.

[17] O. Yamamoto, Influence of particle size on the antibacterial activity of zinc oxide. International Journal of Inorganic Materials, 2001, 3: 643-646.

[18] A. Sirelkhatim, S. Mahmud, A. Seeni, et al., Review on zinc oxide nanoparticles: antibacterial activity and toxicity mechanism. Nano-Micro Letters, 2015, 7: 219-242.

[19] V. Tiwari, N. Mishra, K. Gadani, et al., Mechanism of anti-bacterial activity of zinc oxide nanoparticle against carbapenem-resistant Acinetobacter baumannii. Frontiers in Microbiology, 2018, 9: 1218.

[20] E.P.J. Perez, N.D.F. Soares, J.S.D.R. Coimbra, et al., Zinc oxide nanoparticles: synthesis, antimicrobial activity and food packaging applications. Food and Bioprocess Technology, 2012, 5 :1447-1464.

[21] Y. Liu, L. He, A. Mustapha, et al., Antibacterial activities of zinc oxide nanoparticles against Escherichia coli O157: H7. Journal of Applied Microbiology, 2009, 107: 11931201.

[22] S.R. Senthilkumar, T. Sivakumar, Green tea (Camellia sinensis) mediated synthesis of zinc oxide $(\mathrm{ZnO})$ nanoparticles and studies on their antimicrobial activities. Int. J. Pharm. Pharm. Sci., 2014, 6: 461-465.

[23] B. Fisher, R.P. Harvey, and P.C. Champe, Lippincottss illustrated reviews: Microbiology. Lippincott's illustrated reviews series. Lippincott Williams \& Wilkins, 2007: 367392.

[24] F. Baquero, M.T. Coque, and F. Cruz, Ecology and evolution as targetsthe need for novel Eco-Evo drugs and strategies to fight antibiotic resistance. Antimicrob. Agents Ch., 2011, 55: 3649-3660.

[25] R.J. Fair, Y. Tor, Antibiotics and bacterial resistance in the 21st century. Perspectives in Medicinal Chemistry, 2014, 6: PMC-S14459.

[26] Q.H. Yu, Z.S. Wang, and Q. Yang, Ability of Lactobacillus to inhibit enteric pathogenic bacteria adhesion on Caco2 cells. World J. Microbiol. Bio. Technol., 2012, 27: 881886.

[27] M.S. Jabir, U.M. Nayef, A. Kadhim, et al., Polyethylene glycol-functionalized magnetic $\left(\mathrm{Fe}_{3} \mathrm{O}_{4}\right)$ nanoparticles: A novel DNA-mediated antibacterial agent. Nano Biomedicine \& Engineering, 2019, 11: 18-27.

[28] M.S. Jabir, A.A. Taha, and U.I. Sahib, Linalool loaded on glutathione-modified gold nanoparticles: A drug delivery system for a successful antimicrobial therapy. Artificial Cells, Nanomedicine, and Biotechnology, 2018, 46: 345355.

[29] Y.N. Slavin, J. Asnis, U.O. Häfeli, et al., Metal nanoparticles: understanding the mechanisms behind anti- bacterial activity. Journal of Nanobiotechnology, 2017, 15: 65 .

[30] K.S. Siddiqi, A. Ur Rahman, and A. Husen, Properties of zinc oxide nanoparticles and their activity against microbes. Nanoscale research Letters, 2018, 13: 141.

[31] Y. Xie, Y. He, P.L. Irwin, et al., Antibacterial activity and mechanism of action of zinc oxide nanoparticles against Campylobacter jejuni. Appl. Environ. Microbiol, 2011, 77: 2325-2331.

[32] J.T. Seil, T.J. Webster, Antimicrobial applications of nanotechnology: Methods and literature. International Journal of Nanomedicine, 2012, 7: 2767.

[33] B. Sadeghi, M. Jamali, S. Kia, et al., Synthesis and characterization of silver nanoparticles for antibacterial activity. International Journal of Nano Dimension, 2010, 1: $119-124$.

[34] V.V. Kumar, S.P. Anthony, Antimicrobial studies of metal and metal oxide nanoparticles. Surface chemistry of nanobiomaterials. William Andrew Publishing, 2016: 265-300.

[35] N. Jones, B. Ray, K.T. Ranjit, et al., Antibacterial activity of $\mathrm{ZnO}$ nanoparticle suspensions on a broad spectrum of microorganisms. FEMS Microbiology Letters, 2008, 279: 71-76.

[36] L. Zhang, Y. Jiang, and Y. Ding, Investigation into the antibacterial behaviour of suspensions of $\mathrm{ZnO}$ nanoparticles ( $\mathrm{ZnO}$ nanofluids). Journal of Nanoparticle Research, 2007, 9: 479-489.

[37] T. Ohira, O. Yamamoto, Y. Iida, et al., Antibacterial activity of $\mathrm{ZnO}$ powder with crystallographic orientation. Journal of Materials Science: Materials in Medicine, 2008, 19: 1407-1412.

[38] G. Applerot, A. Lipovsky, R. Dror, et al., Enhanced antibacterial activity of nanocrystalline $\mathrm{ZnO}$ due to increased ROS-mediated cell injury. Advanced Functional Materials, 2009, 19: 842-852.

[39] K.R. Raghupathi, R.T. Koodali, et al., Size-dependent bacterial growth inhibition and mechanism of antibacterial activity of zinc oxide nanoparticles. Langmuir, 2011, 27: 4020-4028.

[40] K.H. Tam, A.B. Djurišić, C.M.N. Chan, et al., Antibacterial activity of $\mathrm{ZnO}$ nanorods prepared by a hydrothermal method. Thin Solid Films, 2005, 516: 61676174 .

Copyright $(\subset$ Araa Mebdir Holi, Sadiyha Yasir Offi Al-Jubory. This is an open-access article distributed under the terms of the Creative Commons Attribution License, which permits unrestricted use, distribution, and reproduction in any medium, provided the original author and source are credited. 